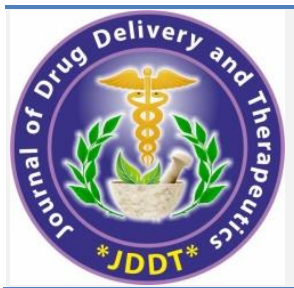

Open Access Full Text Article
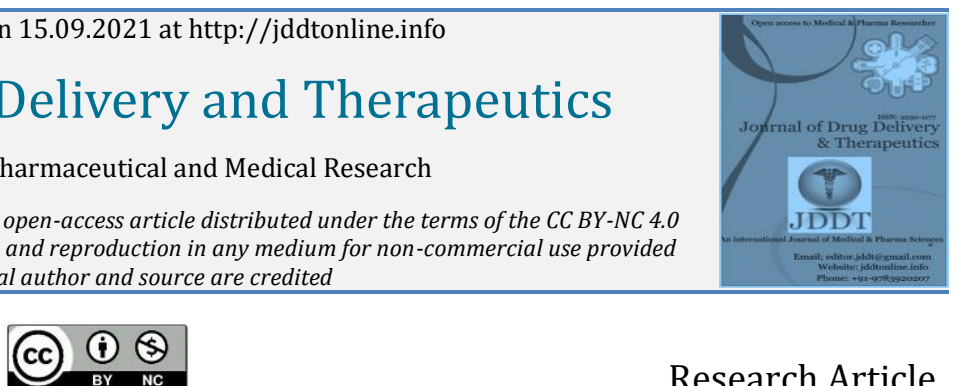

Research Article

\title{
A Comparative Research between Pharmacological and Non- Pharmacological Profile of Anti-Hyperlipidemic Activity on Rodents
}

\author{
*D. Eswar Tony (D), M. Uday Kiran (D), Md. Abu Saleha (D), R. Suresh Naik (D), U. Bhargav Sai (D), V. Niranjan (D), \\ T. Kowshik (D), Rama Rao Nadendla (D)
}

Chalapathi Institute of Pharmaceutical Sciences, Guntur, Andhra Pradesh, India

\section{Article Info:}

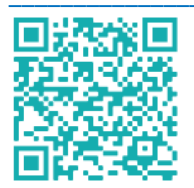

\section{Article History:}

Received 06 July 2021

Reviewed 09 August 2021

Accepted 16 August 2021

Published 15 Sep 2021

\section{Cite this article as:}

Tony DE, Kiran MU, Saleha MA, Naik RS, Sai UB, Niranjan V, Kowshik T, Nadendla RR, A

Comparative Research between Pharmacological and Non-Pharmacological Profile of Anti-

Hyperlipidemic Activity on Rodents, Journal of

Drug Delivery and Therapeutics. 2021; 11(5):65-70

DOI: http://dx.doi.org/10.22270/jddt.v11i5.5016

\section{Abstract}

The condition of hyperlipidemia is found to be a great establisher for all the negative health consequences which may lead to cardiac complications. Continuous usage of medication alone is not permanent remedy but also need physical exercise. The same situation was established in animals to assess the performance of pharmacological and nonpharmacological profile by standardized screening using In-vivo methods. The highcholesterol diet caused a significant increase in total lipids, total cholesterol (TC), total triglycerides (TG), low-density lipoprotein cholesterol (LDL-C), and the atherogenic index, whereas the level of high-density lipoprotein cholesterol (HDL-C) was significantly decreased for the treatment groups intended for physical exercise. This article enables the importance of health benefited by physical performance by depicting the biochemical parameters.

Keywords: Hyperlipidemia, Triglycerides, low-density lipoprotein, activity wheel, Physical exercise, Cardiac performance.

\footnotetext{
*Address for Correspondence:

D. Eswar Tony, Chalapathi Institute of Pharmaceutical Sciences, Chalapathi Nagar, Lam, Guntur, Andhra Pradesh, India

ORCID ID: https://orcid.org/0000-0002-0322-051
}

\section{INTRODUCTION}

Hyperlipidemia means that high levels of fats (or lipids) are in the blood. These fats include cholesterol and triglycerides. They are important for our bodies to function but when they are too high, they can put people at risk for heart disease and stroke $^{1}$. Fats do not dissolve in water. For them to be carried in the blood (which is mostly water) they combine with another substance called a protein to create a lipoprotein (LDL, HDL and VLDL). Too much LDL, or "bad" cholesterol, can build up in the arteries (the blood vessels that carry blood throughout the body) and, over time, cause heart disease or stroke. On the other hand, having too much HDL, or "good" cholesterol, protects the heart by helping to remove the buildup of LDL from the arteries ${ }^{2}$. Low levels of HDL and high triglycerides can also increase fat build up in the arteries and cause heart disease, especially in people who are obese or have diabetes.

Being overweight or obese, not getting enough exercise, and a diet high in saturated fat and cholesterol and low in fruits, vegetables and fiber can play a role in the development of hyperlipidemia ${ }^{3}$. Beyond diet, however, there are other factors that can lead to this condition. Hyperlipidemia generally has no symptoms. Screening is done with a simple blood test to measure levels of cholesterol and triglycerides. According to the National Cholesterol Education Program Guidelines, healthy adults should be screened once every five years starting at age 20. If you have a family history of high cholesterol or other risk factors you may need earlier or more frequent screening 4 .

Hyperlipidemia is treated with changes in diet, weight loss and exercise. If necessary, your doctor will also prescribe medication. The type and dose of the medication will depend on your specific blood fat levels (rather than total cholesterol) and if you have heart disease, diabetes, or other risk factors for heart disease ${ }^{5-7}$. 
Table: 1 Normal level for a lipid profile

\begin{tabular}{|l|l|l|l|}
\hline Lipids & Desirable Value & Border line & High risk \\
\hline Cholesterol & $<200 \mathrm{mg} / \mathrm{dl}$ & $200-239 \mathrm{mg} / \mathrm{dl}$ & $240 \mathrm{mg} / \mathrm{dl}$ \\
\hline Triglycerides & $<140 \mathrm{mg} / \mathrm{dl}$ & $150-199 \mathrm{mg} / \mathrm{dl}$ & $200-499 \mathrm{mg} / \mathrm{dl}$ \\
\hline HDL Cholesterol & $60 \mathrm{mg} / \mathrm{dl}$ & $40-50 \mathrm{mg} / \mathrm{dl}$ & $<40 \mathrm{mg} / \mathrm{dl}$ \\
\hline LDL Cholesterol & $60-130 \mathrm{mg} / \mathrm{dl}$ & $130-159 \mathrm{mg} / \mathrm{dl}$ & $160-189 \mathrm{mg} / \mathrm{dl}$ \\
\hline Cholesterol/HDL Ratio & 4.0 & 5.0 & 6.0 \\
\hline
\end{tabular}

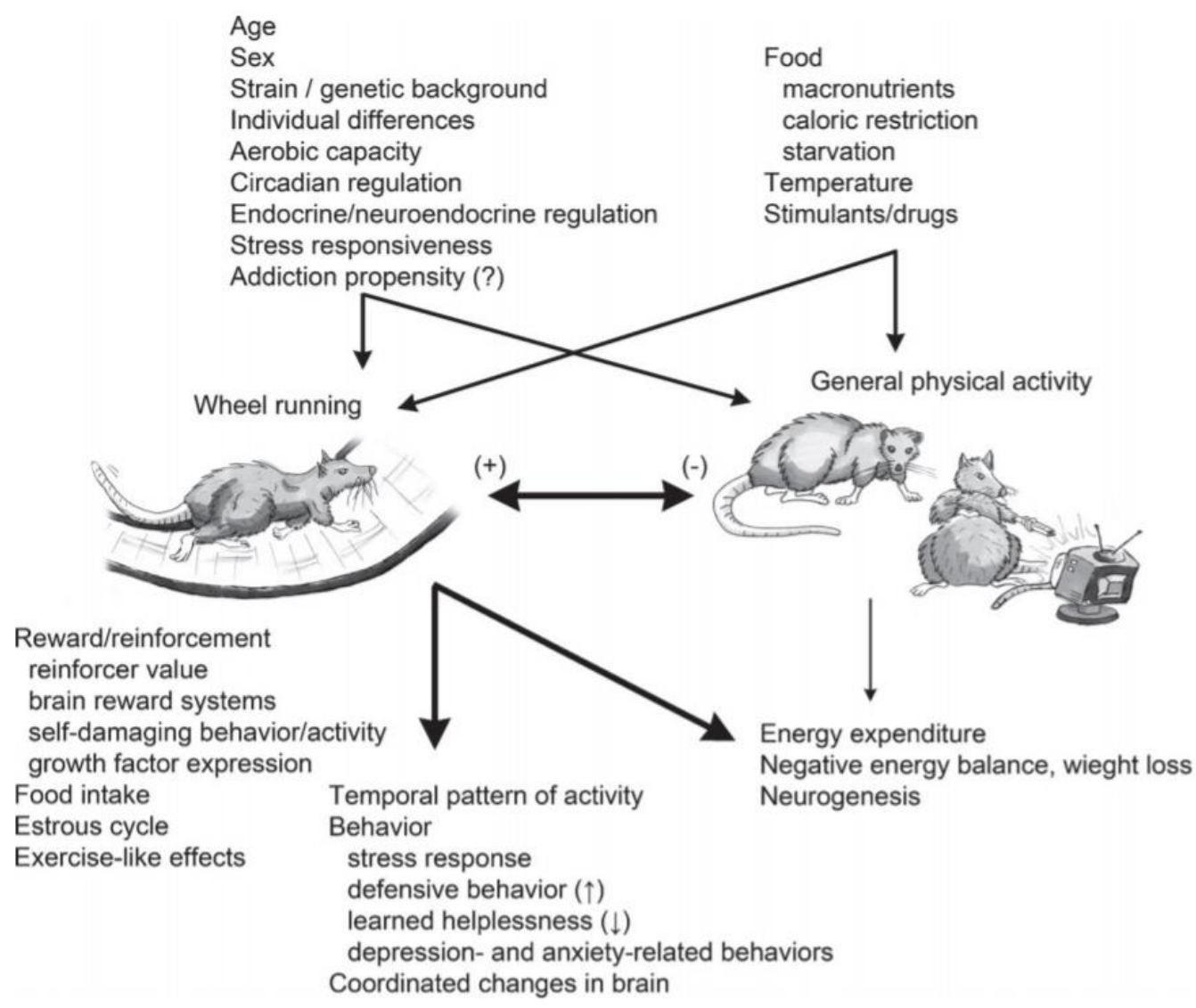

\section{Prevention of Hyperlipidemia ${ }^{8-9}$}

- A low-fat, low-cholesterol diet is recommended.

- Consume soluble fiber-rich foods such as oats, beans, and some fruits.

- Maintaining a healthy weight requires frequent exercise.

The greatest strategy to combat hyperlipidemia is to make small, manageable lifestyle adjustments. However, if lifestyle measures fail to control the illness, cholesterol-lowering medicines must be used.

\section{Treatment of Hyperlipidemia}

The National Cholesterol Education Program (NCEP) was established in 1987 by the National Institute of Health (NIH) under the direction of the Adult Treatment Panel (ATP) for the purpose of disseminating information to health professionals and the general public about hyperlipidemia testing, evaluation, monitoring, and treatment.

\section{(a) Therapeutic lifestyle changes}

Dietary changes, regular physical activity, quitting smoking, and losing weight should be tried first, especially in moderate cases of hyperlipidemia and in people who do not have CHD or CHD risk equivalent and 2 risk factors. It's important to remember that when you're dieting, you're lowering your cholesterol consumption. At the same time, cholesterol production, particularly in the liver, rises. It is recommended that cholesterol intake be limited to 25 percent to 35 percent of total energy intake, with saturated fatty acids accounting for less than $7 \%$ of total energy intake and cholesterol intake being less than $200 \mathrm{mg}$ per day. It is recommended that you consume plant sterol esters and soluble fiber. A good diet can lower cholesterol levels by ten to fifteen percent in the blood ${ }^{10}$.

\section{(b) Drug Therapy}

If you have high LDL, risk factors, or documentation of CHD, you should consider starting pharmacological therapy in addition to TLC. Although monotherapy has been found to be successful in the treatment of hyperlipidemia, a comprehensive approach may necessitate the use of combination medication. Statins, ezetimibe, and bile acid sequestrants are some of the current lipid-lowering medications ${ }^{11}$. 
When dietary changes are insufficient, medication tailored to lower blood cholesterol levels may be administered. Repeated evacuation of blood plasma may be indicated to decrease blood cholesterol levels in rare people with exceedingly high cholesterol levels ${ }^{12}$. Most people need to treat hyperlipidemia for the rest of their lives, which includes both lifestyle changes and medicines.

\section{(c) Pharmacological Treatment}

For the treatment of hyperlipidemia, a variety of hypolipidemic medications are available on the market. The results of the Coronary Drug Project, published in 1975, showed that the medications are unsuccessful in preventing myocardial infarction in patients with pre-existing CHD.

Table: 2 Antihyperlipidemic Drugs

\begin{tabular}{|c|c|c|c|}
\hline Class & Drug & Major effect & $\begin{array}{l}\text { Dose } \\
\text { (mg/dl) }\end{array}$ \\
\hline $\begin{array}{l}\text { HMG Co -A Reductase } \\
\text { inhibitors }\end{array}$ & $\begin{array}{l}\text { Mevastatin } \\
\text { Lovastatin } \\
\text { Pravastatin } \\
\text { Simvastatin }\end{array}$ & $\begin{array}{l}\text { Lowers LDL concentration } \\
\text { Lowers LDL concentration } \\
\text { Lowers LDL concentration } \\
\text { Lowers LDL concentration }\end{array}$ & $\begin{array}{l}20-40 \\
40 \\
30 \\
5-10\end{array}$ \\
\hline Fibrates & $\begin{array}{l}\text { Clofibrate } \\
\text { Gemfibrozil } \\
\text { Fenofibrate } \\
\text { Simfibrate } \\
\text { Etofibrate }\end{array}$ & $\begin{array}{l}\text { Lowers serum TG concentration } \\
\text { Lowers Plasma TG } \\
\text { Lowers plasma LDL concentration and rise HDL concentration } \\
\text { Lowers chol and TG concentration } \\
\text { Lowers VLDL and LDL concentration }\end{array}$ & $\begin{array}{l}2 \mathrm{gm} / \text { day } \\
1.2 \mathrm{gm} \\
2-5 \mathrm{gm} / \text { day } \\
1.5 \mathrm{gm} / \text { day } \\
900 \mathrm{mg} / \text { day }\end{array}$ \\
\hline Antioxidant & Probucol & Lowers plasma chol by $10-15 \%$ & $250-500 \mathrm{mg} /$ day \\
\hline $\begin{array}{l}\text { Other lipid lowering } \\
\text { drugs }\end{array}$ & $\begin{array}{l}\text { Nicotinic acid } \\
\text { Neomycin } \\
\text { Tiademol }\end{array}$ & $\begin{array}{l}\text { Lowers LDL concentration } \\
\text { Lowers LDL concentration } \\
\text { Lowers plasma chol level }\end{array}$ & $\begin{array}{l}2-6 \mathrm{gm} \\
0.5-2 \mathrm{gm} \\
1600 \mathrm{mg}\end{array}$ \\
\hline $\begin{array}{l}\text { Bile acid binding } \\
\text { resins }\end{array}$ & $\begin{array}{l}\text { Cholestryramin } \\
\text { Colestipol }\end{array}$ & $\begin{array}{l}\text { Binds bile acid resulting chol catabolism } \\
\text { Lowers plasma LDL levels }\end{array}$ & $\begin{array}{l}12-16 \mathrm{mg} / \text { day } \\
15-30 \mathrm{mg} / \text { day }\end{array}$ \\
\hline
\end{tabular}

\section{METHODS}

\section{Selection of Animals}

Sprague Dawley rats of either sex (250g-300g) were maintained for 7 days in the animal house of Chalapathi Institute of Pharmaceutical Sciences, Guntur under standard conditions temperature $(24 \pm 10 \mathrm{C})$, relative humidity (45$55 \%)$ and 12:12 light: dark cycle. The animals were fed with standard rat pellet and water ad libitum. The animals could acclimatize to laboratory conditions $48 \mathrm{~h}$ before the start of the experiment. 5 mice/group were used in all sets of experiments. All the experiments were conducted after obtaining permission from the Institutional Animal Ethics Committee (IAEC) Chalapathi Institute of Pharmaceutical Sciences, Guntur (08/IAEC/CLPT/2020-21 (Dt:05-122020).

- GROUP 1 - Control

- GROUP 2 - Negative Control - Diet induced Hyperlipidemia

- GROUP 3 - Standard (Atorvastatin 40mg/kg)

- GROUP 4 - Activity Wheel (Overall Body Performance)

- GROUP 5 - Muscular Strength Maze (Cardio Performance)

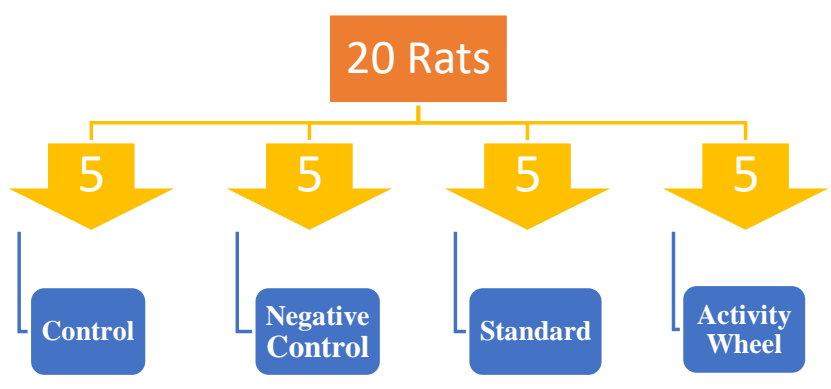

Figure 1: Treatment groups for Anti-hyperlipidemic activity

\section{Hyperlipidemic Diet}

Mixing vanaspati Ghee + coconut oil (3:1 v/v Ration). The Diet was given orally ( $3 \mathrm{mg} / \mathrm{kg} /$ day).

\section{Preparation of Standard Drug}

Standard Atorvastatin at a dose of $40 \mathrm{mg} / \mathrm{kg}$ was prepared by suspending bulk atorvastatin in aqueous $1 \%$ Carboxy Methyl Cellulose was given orally.

\section{Diet induced hyperlipidemic model}

The Animals were selected, weighed then marked for individual identification. In this model, rats were made hyperlipidemic by the oral administration of high fat diet for 14 days by mixing with regular pellet diet. and rats were 
then given with standard Atorvastatin at a dose of $40 \mathrm{mg} / \mathrm{kg}$ orally suspended in in aqueous 1\% Carboxy Methyl Cellulose once daily in the morning for 14 days. During these days, all the groups were given the same dose of high fat diet as before. The hyperlipidemic food and vehicle were given to the control animals ${ }^{13}$. The animals were utilized to analyze several biochemical indicators at the end of the treatment period. Blood was drawn from the rat's orbital plexus under ether anesthesia and spun at $2000 \mathrm{rpm}$ for 30 minutes to obtain serum.

\section{Biochemical Analysis}

The serum samples were analyzed for Total serum Cholesterol (TC), Triglyceride (TG), High Density Lipoprotein
(HDL), Low Density Lipoprotein (LDL), Very Low-Density Lipoprotein (VLDL).

\section{Pharmacological evaluation}

\section{Activity Wheel}

The activity wheel is applicable to assess the overall body performance of the rat/mice. The assessment and evaluation of the wheel is based on the rotating speed of the wheel. More the speed of wheel represents high activeness of animal as it possesses lighter weight ${ }^{14}$. The speed of the activity wheel is observed and recorded using tachometer. The average speed of all treatment groups is assessed and compared for anti-hyperlipidemic activity.
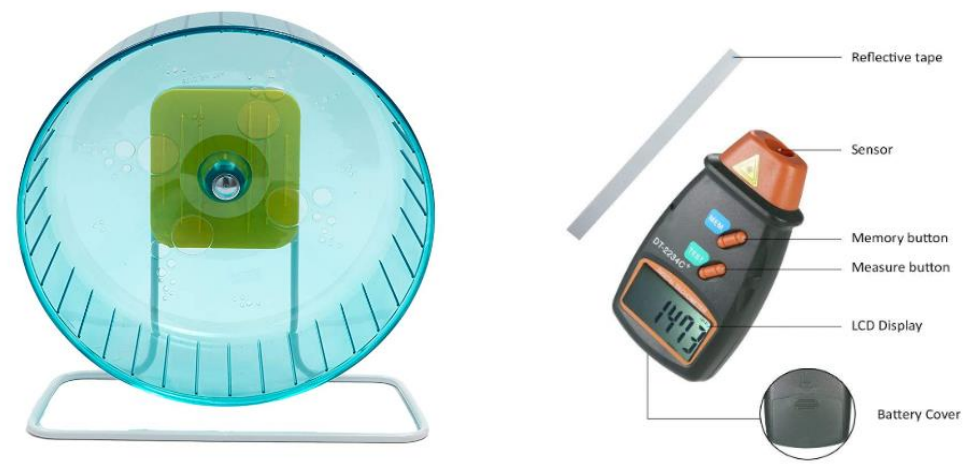

Figure 2: Activity Wheel with tachometer

\section{RESULTS}

The body weights of different treatment groups were assessed at Day 0, Day 7 and Day 14.

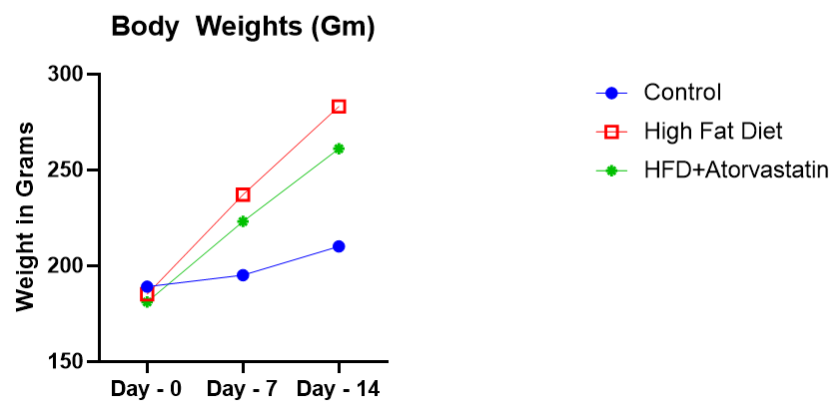

Figure 3: Comparison of Body weights for 14 Days

The serum lipid profiles were assessed for week 1 and week 2 by collecting blood sample from retro orbital puncture.

Serum Lipid Profile (Week-1)

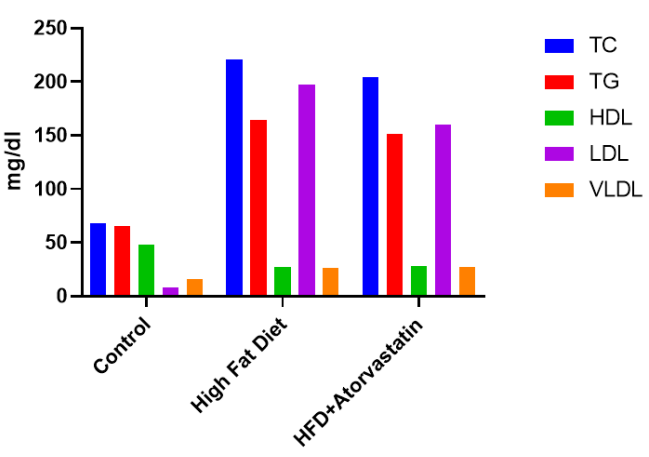

Figure 4: Lipid profile (week 1)

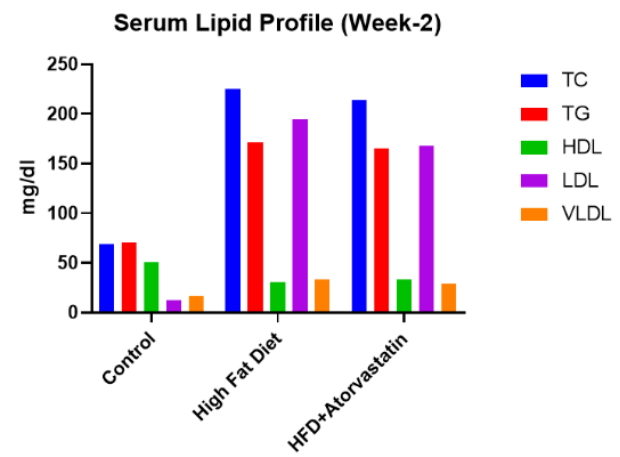

Figure 5: Lipid profile (week 2) 
The performance of animals of all treatment groups on activity wheel was assessed for all weeks. After exposing the treatment groups to physical exercise, the lipid profiles were assessed for week 3 and week 4.

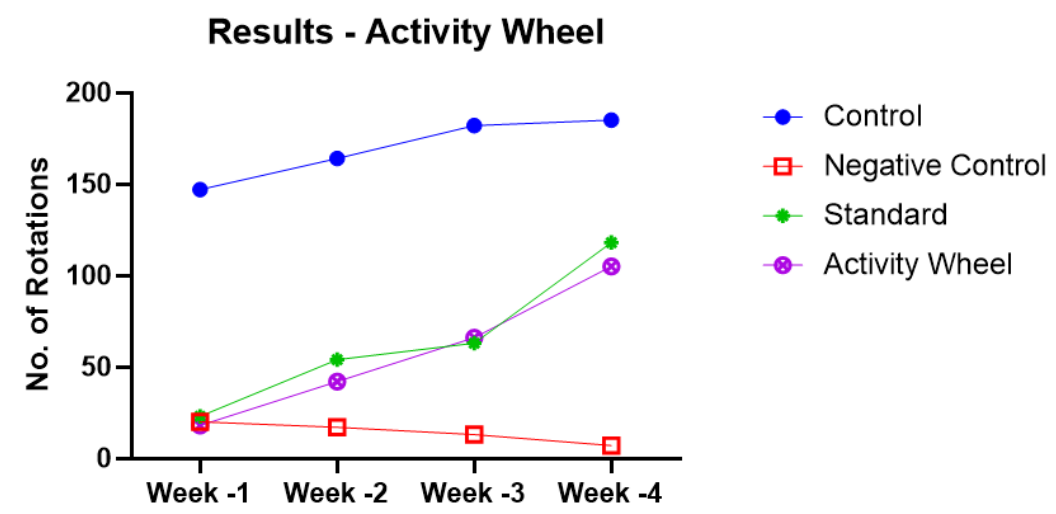

Figure 6: Rotations of Activity wheel for all treatment groups

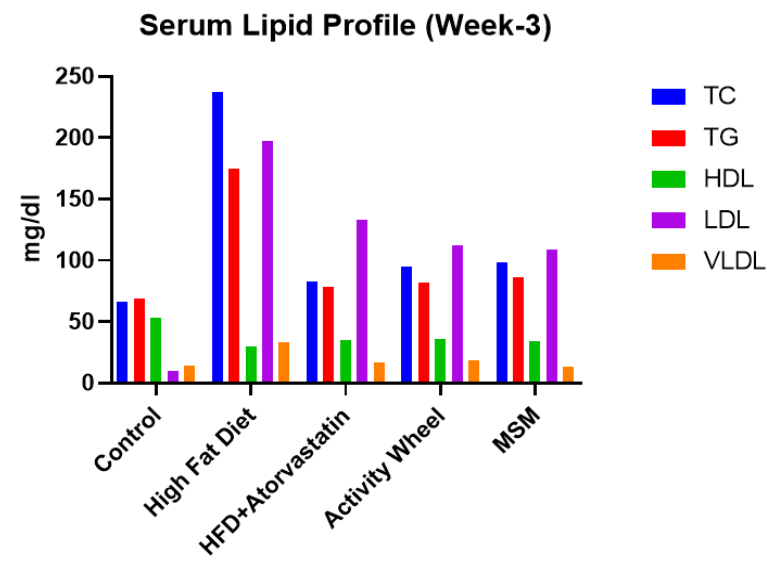

Figure 6: Lipid profile (week 3)

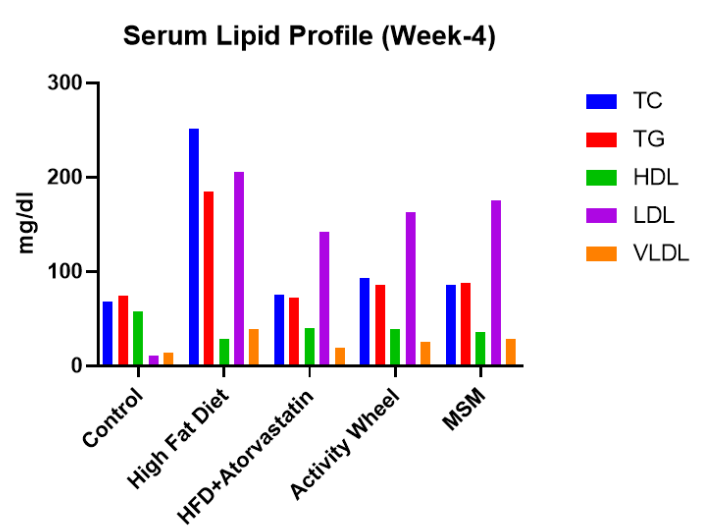

Figure 7: Lipid profile (week 4)

\section{DISCUSSION}

The high fat diet initiated for all treatment groups except control makes the animals to gain weight. The differences in the body weight of various groups is depicted in Table:4. The difference in weight gain was found to be $30-40$ gms at the end of first week and 60-70 gms at the end of 14 days.

After analysing the biochemical parameters for week 1 and week 2, slight variance is found in case of HDL, TC and TG levels, but the variation increases positively following week 3 and 4.

The levels of HDL gradually enhanced during the fourth week in treatment groups related to activity wheel and MSM, which clearly defines the potency of physical exercise than any other pharmacological treatments.

\section{CONCLUSION}

Screening models to evaluate anti-hyperlipidemic activity were standardized using activity wheel and muscle strength maze. The biochemical parameters were evaluated for all treatment groups and the animals which undergone with physical performance found to be active and have controlled TG, TC, HDL and LDL levels.

\section{ACKNOWLEDGEMENT}

All the authors of this article like to take the privilege of expressing cordial thanks to management of Chalapathi
Institute of Pharmaceutical Sciences and also convey sincere gratitude for enabling to prepare this article under the close supervision of department of Pharmacology, Chalapathi Institute of Pharmaceutical Sciences. We sincerely thank our Principal Prof. Rama Rao Nadendla for encouraging us to do such kind of research work.

\section{CONFLICT OF INTEREST}

The authors declare that they have no conflict of interest.

\section{REFERENCES}

1) Gloria A. Otunola1, Oyelola B. Oloyede, Adenike T. Oladiji and Anthony A. Afolayan, Effects of diet-induced hypercholesterolemia on the lipid profile and some enzyme activities in female Wistar rats, African Journal of Biochemistry Research, 2010; 4(6):149-154.

2) Arun Babu Vuyyuru, Sarita Kotagiri, Vrushabendra Swamy BM , Archana Swamy P. Antihyperlipidemic Activity of Ananas Comosus L. Leaves Extract in Albino Rats. RJPBCS, 2012; 3(3):1229-1242.

3) Hayashi T, Hirano T, Yamamoto T, Ito Y, Adachi M. Intensive insulin therapy reduces small dense low-density lipoprotein particles in patients' with type 2 diabetes mellitus, relationship to triglyceride-rich lipoprotein subspecies. Metabolism, 2006; 55(7):879-84. https://doi.org/10.1016/j.metabol.2006.02.014

4) Mendis S, Puska P, Norrving B. Global atlas on cardiovascular disease prevention and control. World Health Organization, 2011. 
5) Singha B, Borah A, Swopna P. Hypolipidemic activity of

Phyllanthus acidus leaves in Hypercholesterolemic diet-induced hyperlipidemia in rats, Sch. J. App. Med. Sci, 2016; 4(10B):36483653.

6) Gloria A. Otunola1, Oyelola B. Oloyede, Adenike T. Oladiji and Anthony A. Afolayan. Effects of diet-induced hypercholesterolemia on the lipid profile and some enzyme activities in female Wistar rats. African Journal of Biochemistry Research, 2010; 4(6):149-154.

7) Bailey J, Day C. Traditional plant medicines as treatments for diabetes. Diabetes Care, 1989; 12:553-64.

https://doi.org/10.2337/diacare.12.8.553

8) Blois MS. Antioxidant determinations by the use of a stable free radical. Nature, 1958; 181:1199-1200. https://doi.org/10.1038/1811199a0

9) Burstein M, Scholnick HR, Morgin R. Rapid method for the isolation of lipoprotein from human serum by precipitation with polyanion. Journal of Lipid Research, 1970; 11:1583-86. https://doi.org/10.1016/S0022-2275(20)42943-8
10) Abedulla Khan K. A preclinical antihyperlipidemic evaluation of Artemisia vulgaris root in diet induced hyperlipidemic animal model. IJPR, 2015; 5(4):110-114.

11) Pandya N, Santani D, Jain S. Antioxidant activity of ezetimibe in hypercholesterolemic rats. Ind. J. Pharmacol, 2006; 38:205-206. https://doi.org/10.4103/0253-7613.25811

12) Arun Babu Vuyyuru, Sarita Kotagiri, Vrushabendra Swamy BM, Archana Swamy P. Antihyperlipidemic Activity of Ananas Comosus L. Leaves Extract in Albino Rats. RJPBCS, 2012 3(3):1229-1242.

13) Singha B, Borah A, Swopna P. Hypolipidemic activity of Phyllanthus acidus leaves in Hypercholesterolemic diet-induced hyperlipidemia in rats, Sch. J. App. Med. Sci, 2016; 4(10B):36483653.

14) Colleen M. Novak et al; The use of a running wheel to measure activity in rodents: Relationship to energy balance, general activity, and reward. Neuroscience and Biobehavioral Reviews 2012; 36:1001-1014.

https://doi.org/10.1016/j.neubiorev.2011.12.012 